\title{
Retinal degeneration triggered by inactivation of PTEN in the retinal pigment epithelium
}

\author{
Jin Woo Kim, ${ }^{1,4}$ Kyung Hwa Kang, ${ }^{1}$ Patrick Burrola, ${ }^{2}$ Tak W. Mak, ${ }^{3}$ and Greg Lemke ${ }^{2,5}$ \\ ${ }^{1}$ Department of Biological Sciences, Korea Advanced Institute of Science and Technology, Daejeon 305-701, South Korea; \\ ${ }^{2}$ Molecular Neurobiology Laboratory, The Salk Institute, La Jolla, California 92037, USA; ${ }^{3}$ The Campbell Family Institute \\ for Breast Cancer Research, University Health Network, Toronto, Ontario M5G 2C1, Canada
}

\begin{abstract}
Adhesion between epithelial cells mediates apical-basal polarization, cell proliferation, and survival, and defects in adhesion junctions are associated with abnormalities from degeneration to cancer. We found that the maintenance of specialized adhesions between cells of the retinal pigment epithelium (RPE) requires the phosphatase PTEN. RPE-specific deletion of the mouse pten gene results in RPE cells that fail to maintain basolateral adhesions, undergo an epithelial-to-mesenchymal transition (EMT), and subsequently migrate out of the retina entirely. These events in turn lead to the progressive death of photoreceptors. The C-terminal PSD-95/Dlg/ZO-1 (PDZ)-binding domain of PTEN is essential for the maintenance of RPE cell junctional integrity. Inactivation of PTEN, and loss of its interaction with junctional proteins, are also evident in RPE cells isolated from $\mathrm{ccr2}^{-/-}$mice and from mice subjected to oxidative damage, both of which display age-related macular degeneration (AMD). Together, these results highlight an essential role for PTEN in normal RPE cell function and in the response of these cells to oxidative stress.
\end{abstract}

[Keywords: PI3K signaling; PTEN; retinal pigment epithelium (RPE); epithelial-to-mesenchymal transition (EMT); age-related macular degeneration (AMD)]

Supplemental material is available at http://www.genesdev.org.

Received May 28, 2008; revised version accepted September 12, 2008.

The vertebrate retina is an exquisitely organized ensemble of neurons and glia, whose integrated activity eventually delivers visual information to the brain (Morrow et al. 1998; Livesey and Cepko 2001). Visual perception, however, requires not only this "neural retina," but in addition, a set of large, neuroepithelially derived cells located at the back of the eye-the cells of the retinal pigment epithelium (RPE) (Bok 1993; Grierson et al. 1994; Marmorstein et al. 1998; Zarbin 1998; Adler et al. 1999; Schraermeyer and Heimann 1999). RPE cells, through their apical microvili, make extensive contacts with the opsin-containing outer segments of photoreceptors (Bok 1993; Rizzolo 1997; Marmorstein et al. 1998). This association enables these cells to exchange photopigments with, uptake metabolic wastes from, and transfer nutrients to photoreceptors. In addition, RPE cells perform a specialized form of phagocytosis in which the distal ends of photoreceptor outer segments are pinched off, engulfed, and metabolized on a daily basis (Young and Bok 1969; Edwards and Szamier 1977; Bok 1993).

Corresponding authors.

${ }^{4}$ E-MAIL jinwookim@kaist.ac.kr; FAX 82-42-350-2610.

${ }^{5}$ E-MAIL lemke@salk.edu; FAX (858) 455-6138.

Article published online ahead of print. Article and publication date are online at http://www.genesdev.org/cgi/doi/10.1101/gad.1700108.
This homeostatic phagocytosis is critical, since defects in the process invariably lead to photoreceptor death (Young and Bok 1969; Edwards and Szamier 1977; Bok 1993). On their basal surfaces, RPE cells adhere to Bruch's membrane, which separates them from the blood vessels that run just outside the retina (Bok 1993; Rizzolo 1997; Marmorstein et al. 1998; Zarbin 2004). These polarized features of the RPE, which are essential to its function, require specialized intercellular junctions (Rizzolo 1997; Jin et al. 2002).

Junctional structures depend upon cytoplasmic linker proteins that recruit cytoskeletal proteins to adhesion complexes (Vasioukhin et al. 2000; Jamora and Fuchs 2002; Perez-Moreno et al. 2003). $\beta$-Catenin, for example, associates with cadherins to form adherens junctions (AJs) on the lateral aspect of epithelial cells, and links the actin cytoskeleton to these junctions (Perez-Moreno et al. 2003). Alternatively, free $\beta$-catenin, generated by dissociation from cadherins in response to growth factor stimulation and oxidative stress, translocates to the nucleus, where it regulates genes that lead epithelial cells to re-enter the cell cycle. In some settings, this results in cancer (Barker and Clevers 2000).

Since RPE cells form an important component of the blood-retinal barrier (BRB), RPE damage or loss invari- 
ably results in retinal degeneration (Rizzolo 1997; Hamdi and Kenney 2003; Zarbin 2004). Although impairment of RPE structural integrity is known to lead to retinal degenerative diseases such as age-related macular degeneration (AMD) and some forms of retinitis pigmentosa $(\mathrm{RP})$, the molecular mechanisms that regulate RPE structure have remained elusive (Grierson et al. 1994; Zarbin 1998; Adler et al. 1999; Schraermeyer and Heimann 1999|. One of the major causes of AMD is oxidative stress, which is generated both endogenously during the course of phototransduction, and also by a variety of exogenous insults (Cai et al. 2000; Bailey et al. 2004; Wenzel et al. 2005). AMD-inducing oxidative stresses impact the phosphoinositide 3-kinase (PI3K)-Akt pathway (Lee et al. 2002; Leslie et al. 2003; Yang et al. 2006; Barbieri et al. 2008), and it has been proposed that this pathway protects RPE cells against the deleterious effects of oxidative stress (Wang and Spector 2000; Defoe and Grindstaff 2004; Yang et al. 2006).

We investigated this hypothesis by inducing extended activation of the PI3K-Akt pathway in the mouse RPE through specific deletion of the phosphatase and tensin homolog deleted on chromosome 10 (pten) gene. We find that PTEN inactivation leads to the progressive degeneration of both RPE cells and the photoreceptors with which they interact. PTEN-deficient RPE cells gradually lose their intercellular adhesions, undergo an epithelialto-mesenchymal transition (EMT), and eventually disappear from the eye entirely. We also found that PTEN is physiologically inactivated in RPE cells isolated from $\mathrm{ccr2}^{-/-}$mice or from mice treated with an oxidative stressor, both of which exhibit retinal degeneration. We propose that PTEN plays a central role in normal retinal homeostasis, in the maintenance RPE cell polarity and integrity, and in the protection against oxidative stressinduced retinal degeneration.

\section{Results}

\section{RPE-specific knockout of pten}

We used immunostaining to examine the activity of the PI3K and Akt pathways in the adult mouse retina. We first assessed the distribution of phosphorylated Akt(S473; pAkt), which appears upon the activation of PI3K and the subsequent elevation of phosphatidylinositol 3,4,5-triphosphate (PIP3) levels in the plasma membrane (Cantley 2002). Phospho-Akt was concentrated in the inner nuclear layer (INL) and the ganglion cell layer (GCL) of the retina, with a relatively low signal in the outer nuclear layer (ONL) and the RPE layer (Fig. 1A, middle, right panels). When we examined the distribution of PTEN, whose phosphoinositide 3-phosphatase opposes PI3K (Salmena et al. 2008), we found an inverse pattern of expression (Fig. 1A,B). PTEN was highest in RPE layer, where the pAkt signal was relatively low, and lowest in the pAkt-enriched INL. PTEN was also high in RGC axons, where pAkt was low, and low in RGC cell bodies, where pAkt was high.

The RPE supports visual processes through the re-
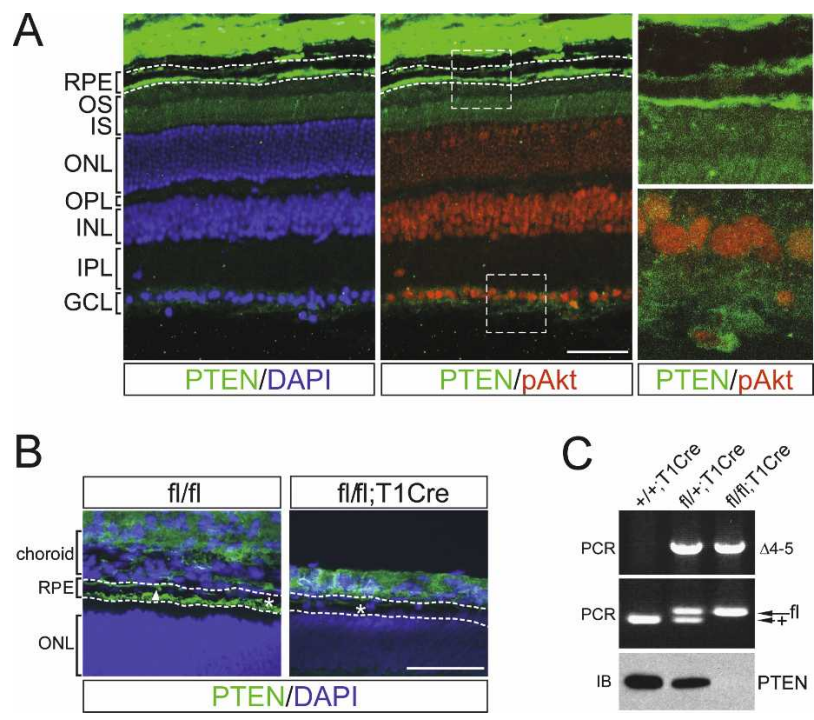

Figure 1. RPE-specific deletion of mouse PTEN. $(A)$ Expression of PTEN in the adult retina. A section of a 3-mo-old mouse eye was stained with mouse anti-PTEN antibody (green) with counter-nuclear staining with DAPI (blue, left panel). PTEN is enriched in the RPE layer where the signal for anti-phosphoAkt(S473) (pAkt; red, middle and right panels) is lowest. Boxed areas in the middle panel are enlarged in right panels to provide closer views to the costaining images of PTEN and pAkt at RPE-photoreceptor boundary (top right panel) and at GCL (bottom right panel). Upper and lower dashed lines represent basal and apical extents of the RPE layer, respectively. (OS) Photoreceptor outer segment; (IS) inner segment; (ONL) outer nuclear layer (photoreceptor nuclei); (OPL) outer plexiform layer; (INL) inner nuclear layer; (IPL) inner plexiform layer; (GCL) retinal ganglion cell layer. (B) PTEN localizes to apical microvilli (*) and basolateral areas (arrowhead) of RPE cells in P8 $\mathrm{fl} / \mathrm{fl}$ mice. This signal is absent in $\mathrm{fl} / \mathrm{fl}$; T1Cre RPE cells, while PTEN in the choroids, sclera, or retina is intact. Upper and lower dashed lines represent basal and apical extents of the RPE layer, respectively. ( $C$, top panel) RPE cells were isolated from P8 eyes, and Cre-mediated deletion of the genomic fragment spanning exons 4 and 5 of PTEN gene $(\Delta 4-5)$ (Suzuki et al. 2001) was examined by PCR. The middle panel displays corresponding genotyping PCR using tail DNA, where Cre is not expressed. (Bottom panel) Loss of PTEN in the RPE was confirmed by immunoblot (IB) with PTEN antibody. Bars, $50 \mu \mathrm{m}$.

moval of spontaneously generated toxic metabolites and the phagocytic renewal of photoreceptor outer segments (Bok 1993; Grierson et al. 1994; Marmorstein et al. 1998; Zarbin 1998; Adler et al. 1999; Schraermeyer and Heimann 1999). Given the high level of PTEN in the RPE, we investigated its role in this epithelium by generating mice that lack the phosphatase specifically in RPE cells (Fig. 1B,C). Mice carrying a "floxed" pten allele were bred with mice expressing Cre recombinase under the control of the RPE-restricted tyrosinase-related protein 1 (TRP1) promoter (Suzuki et al. 2001; Mori et al. 2002). As expected, exons 4 and 5 of PTEN gene, which are flanked by two loxP sites, were deleted in RPE cells isolated from PTEN ${ }^{\mathrm{fl} / \mathrm{fl}}$; TRP1-Cre mice $(\mathrm{fl} / \mathrm{fl}$; T1Cre hereafter) (Fig. 1B,C), and these cells lacked PTEN protein. 
The mutant mice did not show any recognizable defects in embryonic development or reproduction.

\section{Photoreceptor degeneration and retinal depigmentation}

The loss of PTEN from the RPE did not result in morphological defects in embryonic or neonatal (P0) eyes (data not shown). However, fl/fl;T1Cre retinae underwent progressive degeneration from this time forward (Fig. 2). Changes were first detected at $1 \mathrm{wk}$ (P8), when local depigmentation associated with local collapse of RPE cells and choroids was detected in $\sim 17 \%$ of mutant eyes. ONL thickness, as well as the number of photoreceptors, was also reduced in the mutants, although all retinal cell types were present (Fig. 2A,B; Supplemental Fig. S1A,B). Morphological changes were more evident at $1 \mathrm{mo}$, when expansive depigmented areas and disorganization of retinal laminae were readily evident (Fig. $2 \mathrm{C}, \mathrm{D})$, and the total number of photoreceptors was markedly reduced (Supplemental Fig. S1A,B). By 3 mo, $\mathrm{fl} / \mathrm{fl}$; T1Cre retinae exhibited a dramatic loss of photoreceptors, and remaining retinal cells failed to form noticeable laminar structures (Fig. 2E,F). Most mutant eyes $(\sim 78 \%)$ were obviously depigmented at this point (Fig. $\left.2 \mathrm{E}^{\prime}, \mathrm{F}^{\prime}, \mathrm{H}\right)$. More than $90 \%$ of RPE cells were lost from 3-mo-old mutant eyes (Fig. 2I), but this cell loss did not appear to result from apoptotic cell death, since no elevation in the number of TUNEL-positive or activated caspase-3-positive cells (relative to wild type) was detected in the $\mathrm{fl} / \mathrm{fl}$; T1Cre mice at any stage (data not shown).

\section{Retinal gliosis}

Despite the severe loss of photoreceptors, the overall thickness of 3-mo-old mutant retinae was only slightly reduced relative to wild type (Fig. 2E,F). This discrepancy was accounted for by the proliferation of activated Müller glia (MG), marked by glutamine synthase (GS) and glial fibrillary acidic protein (GFAP) (Supplemental Fig. S3A-D). The overproduction of MG in the mutant retina is common to many retinal degenerative diseases
(Bringmann and Reichenbach 2001), and is normally induced by the inflammation that is triggered by infiltrating macrophages and monocytes. We monitored the distribution of macrophages by immunostaining with the pan-macrophage marker F8/40 (Malorny et al. 1986). F8/ 40-positive macrophages were confined outside of the RPE layer in wild-type mouse eyes, but were detected in the subretinal spaces and the inner plexiform layer (IPL) of $\mathrm{fl} / \mathrm{fl}$; T1Cre mouse retinae (data not shown).

\section{Loss of intercellular adhesions}

In order to determine the origin of these degenerative events, we examined the ultrastructure of mutant and wild-type RPE cells by electron microscopy (EM) (Fig. 3). EM images of RPE cells from 4-wk-old fl/fl;T1Cre mice, which exhibited early-stage retinal degeneration, provided a comprehensive view of retinal degeneration in a single eye (Fig. 3B,C). Mutant eyes included a severely affected region, where most RPE cells and a substantial number of photoreceptors had degenerated, but also contained areas with a relatively intact RPE-photoreceptor interface (Fig. 3B,C). Closer examination of these intact areas revealed very different cellular structures from those seen in PTEN heterozygous RPE cells (Fig. 3D,E). Heterozygous RPE cells contacted each other with AJs and desmosomes at their lateral margins, and with intact tight junctions (TJs) at their apical margins (Fig. 3A,D). They also formed regular membrane folds along their basal surfaces contacting Bruch's membrane. Although small vacuolar "bubbles" between lateral contacts in heterozygous RPE cells were not uncommon, these were enormously increased in PTEN-deficient RPE cells (brackets in Fig. 3A,B). Basolateral RPE adhesions were completely lost in the mutants, leaving only thin bands of cell-to-cell contact at apical TJs (Fig. 3E,F). In contrast, the apical microvilli of the mutant RPE cells projected normally, and made normal contacts with photoreceptor outer segments (Fig. 3E,F). These ultrastructural changes were accompanied by an abnormal subcellular distribution of marker proteins (Supplemental Fig. S4). Junctional localization of the AJ components $\beta$-catenin and E-cadherin was defective in PTEN-deficient RPE cells
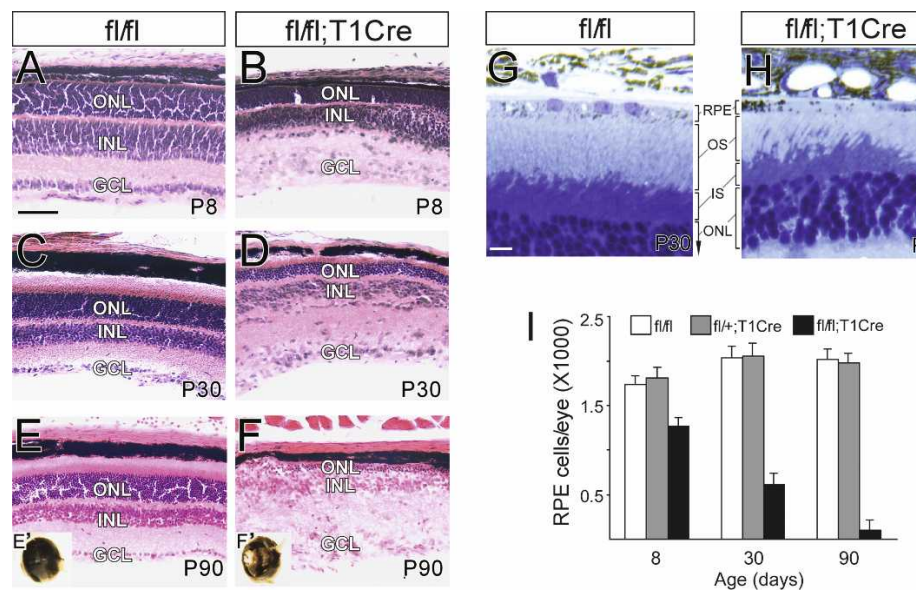

Figure 2. Progressive RPE loss in $\mathrm{fl} / \mathrm{fl}$; $\mathrm{T} 1 \mathrm{Cre}$ eyes. $(A-$ F) H\&E staining of $\mathrm{fl} / \mathrm{fl}$ and $\mathrm{fl} / \mathrm{fl}$; T1Cre eye sections at the indicated postnatal $(P)$ days. Images in $E^{\prime}$ and $F^{\prime}$ are lateral views of 3-mo-old $\mathrm{f} / \mathrm{fl}$ and $\mathrm{fl} / \mathrm{fl}$; T1Cre eyes, respectively. $(G, H)$ Osmium tetroxide staining of 1-moold $\mathrm{f} / \mathrm{fl}$ and $\mathrm{fl} / \mathrm{fl}$; T1Cre eye sections. (I) Total RPE cells were purified from eyes at the indicated postnatal day, dissociated, and counted. $(n \geq 6)$ (see the Materials and Methods for details). Bars: $A-F, 50 \mu \mathrm{m} ; G, H, 10 \mu \mathrm{m}$. 

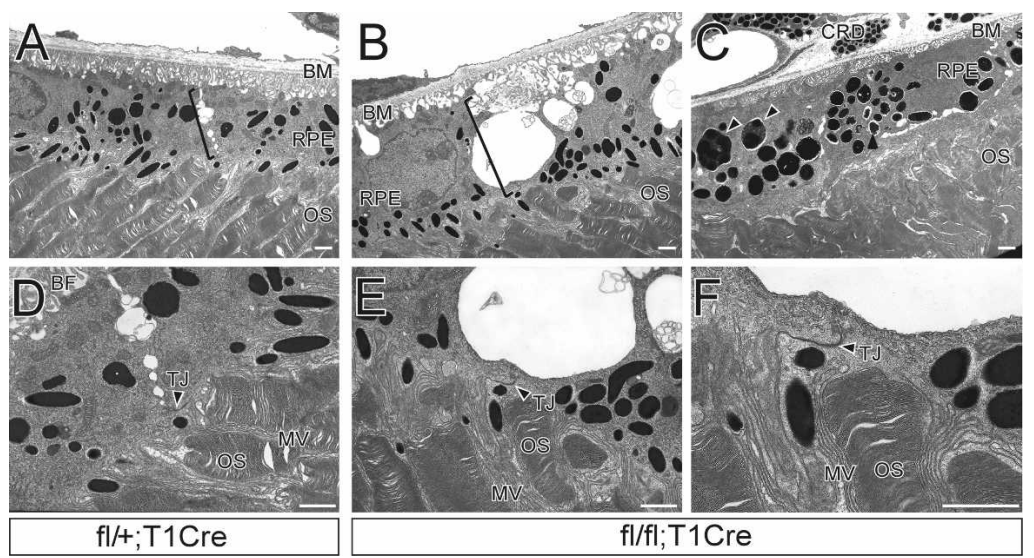

Figure 3. Impaired intercellular adhesion between PTEN-deficient RPE cells. EM images from P28 fl/ + ; T1Cre $(A, D)$, and $\mathrm{fl} / \mathrm{fl}$; T1Cre $(B, C, E, F)$ mouse eyes. $\mathrm{fl} /+$; T1Cre RPE cells form well-organized basolateral appositions (bracket in $A$ ), but PTEN-deficient RPE lose these appositions, resulting in large intercellular vacuoles (bracket in $B$ ). Basal folds of the mutant RPE cells, which contact Bruch's membrane (BM), degenerate (B), and many RPE cells contain enlarged, dysmorphic pigment vesicles (arrowheads in $C$ ). $(D, E)$ Magnified EM images of $A, B$, and $E$ are shown in $D, E$, and $F$, respectively. (TJ) Tight junction; (MV) microvilli; (OS) outer segments; (CRD) choroid. Bars, $1 \mu \mathrm{m}$.
(Supplemental Fig. S4A-D), but the apical localization of Ezrin in the microvilli of mutant RPE cells that had not degenerated was normal (Supplemental Fig. S4E,F), as was that of zona occludens 1 (ZO1) and Crumb3 (Crb3), proteins that associate with TJs (Supplemental Fig. S4GJ). These data suggest that the progressive RPE degeneration and subsequent photoreceptor degeneration in the $\mathrm{fl} / \mathrm{fl}$; T1Cre mice begin with defects in basolateral junctional structures, which are followed by the disruption of apical structures and the subsequent loss of overall BRB integrity.

\section{Localization of PTEN at junctional areas}

We did not expect that basolateral structures would be most sensitive to the loss of PTEN, since PTEN is especially prominent in the apical membrane of RPE cells, as it is in many other epithelial cells (Pinal et al. 2006; Martin-Belmonte et al. 2007). We therefore re-examined the intracellular distribution of PTEN in vivo and in primary cultured RPE cells (Supplemental Fig. S5). PTEN was dispersed in the cytoplasm of RPE cells at P0, but was more apically concentrated at P8 (Supplemental Fig. S5A-D). Apical PTEN was maintained thereafter, expanding along microvilli by P28 (Supplemental Fig. S5E,F). PTEN could be also detected at the basolateral surfaces of P8 and P28 RPE cells (Fig. 1B; Supplemental Fig. S5C-F). Basolateral PTEN was more evident in cultured mouse RPE cells grown as a single layer on Matrigel (Supplemental Fig. S5G-I).

The localization and relative level of PTEN at the basolateral surface of RPE cells were further examined by differential fixation and detergent extraction (Supplemental Fig. S5J,K; see the Supplemental Material for details). The majority of PTEN was detected in the apical area, cytoplasm, and nuclei of RPE cells when primary cultured RPE cells were fixed prior to extraction with Triton X-100 (Supplemental Fig. S5J). PTEN at basolateral junctional structures was more obvious when RPE cells were subjected to extraction of apical, cytosolic, and soluble nuclear proteins prior to fixation (Supplemental Fig. S5K). Quantification of PTEN levels, assessed by densitometric measurement of band intensities on Western blots of the Triton X-100 soluble versus insoluble fraction, indicated that basolateral PTEN accounts for $25 \%$ of total PTEN in RPE cells (Supplemental Fig. S5L).

\section{Junctional PTEN requires its C-terminal PSD-95/Dlg/ZO-1 (PDZ)-binding domain}

PTEN possesses two enzymatic activities. One is a lipid phosphatase that acts on the 3-position of PIP3 to produce phosphatidylinositol-4,5 bisphosphates (PIP2), and the other is a protein phosphatase that preferentially dephosphorylates phosphotyrosine residues (Li et al. 1997; Myers et al. 1997; Steck et al. 1997; Maehama and Dixon 1998). To address the relative contribution of these two phosphatase activities to the maintenance of basolateral structures in RPE cells, retroviruses expressing various versions of human PTEN were used to infect cultured PTEN-deficient RPE cells isolated from $\mathrm{fl} / \mathrm{fl}$; T1Cre mice, and the subcellular distribution of $\beta$-catenin was monitored (Fig. 4). Infection with retroviruses expressing wild-type PTEN remobilized $\beta$-catenin to AJs from the cytoplasm and nuclei of PTEN-deficient RPE cells (Fig. 4A,B). A mutant PTEN lacking lipid phosphatase activity [PTEN(G129E)] (Furnari et al. 1997; Myers et al. 1998) was also able to remobilize $\beta$-catenin to AJs, although it was less effective than wild type (Fig. 4C; Supplemental Fig. S6). However, PTEN(G129R), which lacks both lipid and protein phosphatase activity (Furnari et al. 1997), failed to remobilize $\beta$-catenin to AJs (Fig. 4D; Supplemental Fig. S6). These results suggest that PTEN regulates junctional structures through the dephosphorylation of substrate proteins, but also through local control of the balance between PIP2 and PIP3.

We next sought to define the functional domains by which PTEN facilitates $\beta$-catenin relocalization to AJs (Fig. 4E,F). PTEN might localize to AJs through the binding to phospholipids with its C2 domain, or through the interaction of junctional PDZ domain-containing proteins with its C-terminal PDZ-binding domain (Georgescu et al. 1999, 2000; Lee et al. 1999; Leslie et al. 2000). Retroviruses expressing a mutant PTEN that lacks a functional C2 domain (PTEN M-CBR3) (Lee et al. 1999; Leslie et al. 2000) remobilized $\beta$-catenin to AJs even more efficiently than wild type PTEN in PTEN- 

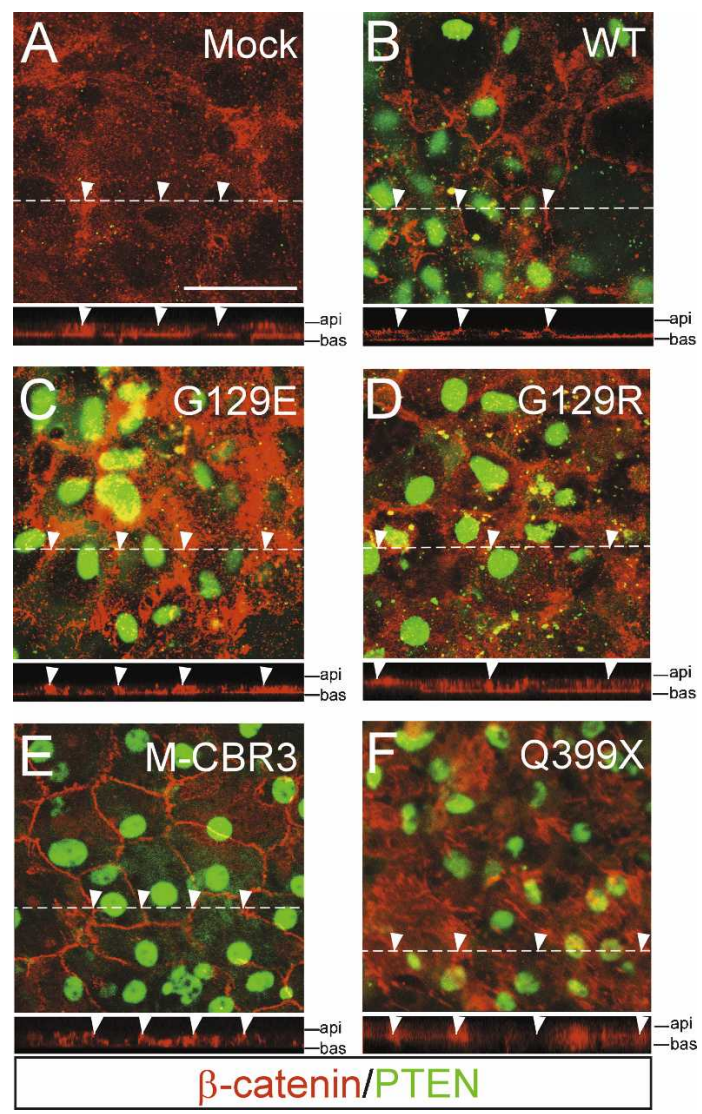

Figure 4. The PDZ-binding domain of PTEN is essential for RPE AJs. RPE cells isolated from $\mathrm{fl} / \mathrm{fl}$; T1Cre mice were cultured on the Matrigel-coated transwell plates, and either mock-infected $(A)$ or infected with retroviruses expressing wild-type PTEN (B), a lipid phosphatase-defective PTEN(G129E) mutant $(C)$, a phosphatase-null PTEN(G129R) mutant $(D)$, a mutant lacking lipid-binding $\mathrm{C} 2$ domains (M-CBR3; E), or a truncated PTEN mutant lacking the C-terminal PDZ-binding domain $(\mathrm{Q} 399 \mathrm{X} ; F)$. The localization of $\beta$-catenin in RPE cells was examined at $36 \mathrm{~h}$ of post-infection by immunostaining with anti$\beta$-catenin antibody (red) and counterstaining with anti-PTEN antibody (green). For each panel, the fine dashed line indicates the position of the section for the orthogonal Z-stack displayed at the bottom of the panel, and arrowheads on the dashed line correspond to arrowheads in the bottom panel. Api and bas indicate apical and basal surfaces of the Z-stack. Bar, $50 \mu \mathrm{m}$.

deficient RPE cells (Fig. 4E; Supplemental Fig. S6). In contrast, PTEN(Q399X), which carries a nonsense mutation truncating the C-terminal PDZ-binding domain (Leslie et al. 2000), was unable to deliver cytoplasmic $\beta$-catenin to AJs (Fig. 4F). These results strongly suggest that the maintenance of AJs by PTEN requires interaction with PDZ domain-containing junctional proteins.

\section{RPE inactivation of PTEN in mice undergoing retinal degeneration}

To understand the molecular events that might lead to the structural changes documented above, we isolated total RNA from P21 wild-type or PTEN-deficient RPE cells, and analyzed gene expression profiles by Affymetrix microarrays (Supplemental Table S1). Consistent with the appearance of defective junctional structures in the mutant RPE cells, genes involved in cell-tocell adhesion, including E-cadherin, desmoplakin, and plakophilin 3, were markedly reduced in their expression in the mutant RPE cells. Also reduced were genes tied to the inhibition of cell proliferation, such as transformation-related protein 63 (Trp63), p107Rb, and c-Cbl; genes regulating the extracellular matix (ECM), such as thrombospondin 4, dermatospondin, and syndecan 1 ; and genes encoding intracellular chaperons, such as the heat-shock proteins Hspala, Hspalb, Hspb1, and Dnaja4 (Supplemental Table S1). In contrast, the expression of genes associated with cell movement, such as $\alpha$-smooth muscle actin/Actin A2a ( $\alpha$-SMA/ActA2a) and the myosin heavy chains Myh1 and Myh4, was markedly elevated in the mutant RPE cells (Supplemental Table S1).

Among the gene families that underwent the most dramatic changes were those encoding the crystallins and heat-shock proteins (HSPs). HSPs and crystallins protect cells against protein-destabilizing stressors, such as elevated temperature and reactive oxygen species (Horwitz 2000; Wang and Spector 2000; Bailey et al. 2004). RPE cells are continuously exposed to oxidative stress from the metabolic intermediates of photochemical reactions (Winkler et al. 1999; Cai et al. 2000), and excessive oxidative stress is known to be one of the major causes of retinal degenerative diseases such as AMD (Winkler et al. 1999; Beatty et al. 2000; Decanini et al. 2007).

In order to assess any phenotypic similarity between PTEN-deficient RPE cells and AMD RPE cells, we monitored the cellular distribution of $\beta$-catenin and Ezrin in RPE cells of CC chemokine receptor 2-deficient $\left(\mathrm{ccr}^{-/-}\right)$ mice, which have been advanced as an AMD animal model (Fig. 5A; Ambati et al. 2003). An increased distribution of $\beta$-catenin in the cytoplasm coupled with normal localization of Ezrin in the apical microvilli, similar to that seen in PTEN-deficient RPE cells, was also observed in the cells of $\mathrm{ccr}^{-/-}$mice (Fig. 5A; Supplemental Fig. S4B,F); and the immunofluorescent signal for PTEN at the apical and basolateral regions of $c c r 2^{-/-}$RPE cells was also strikingly reduced (Fig. 5A). However, the total amount of PTEN in RPE cells was not significantly changed (Fig. 5B). Instead, the level of phosphorylation of PTEN at S380, T382, or T383 (pPTEN), all of which decrease its association with PDZ domain proteins as well as its enzymatic activity (Vazquez et al. 2000; Tolkacheva et al. 2001), was substantially elevated in $\mathrm{ccr2}^{-/}$ RPE cells (Fig. 5B). Similar changes in these proteins were also observed in RPE cells of the $c c 12^{-/-}$AMD mouse model (Ambati et al. 2003) (data not shown). These data suggest that the PTEN of $c c r 2^{-/-}$RPE cells is not able to integrate into junctional structures through its C-terminal PDZ-binding domain (Fig. 4E). This in turn suggests that either genetically or physiologically induced PTEN inactivation can result in AMD in mice.

To address whether the inactivation of PTEN at junctional areas is an event commonly induced by AMDtriggering stimuli or an event that results from defects in 

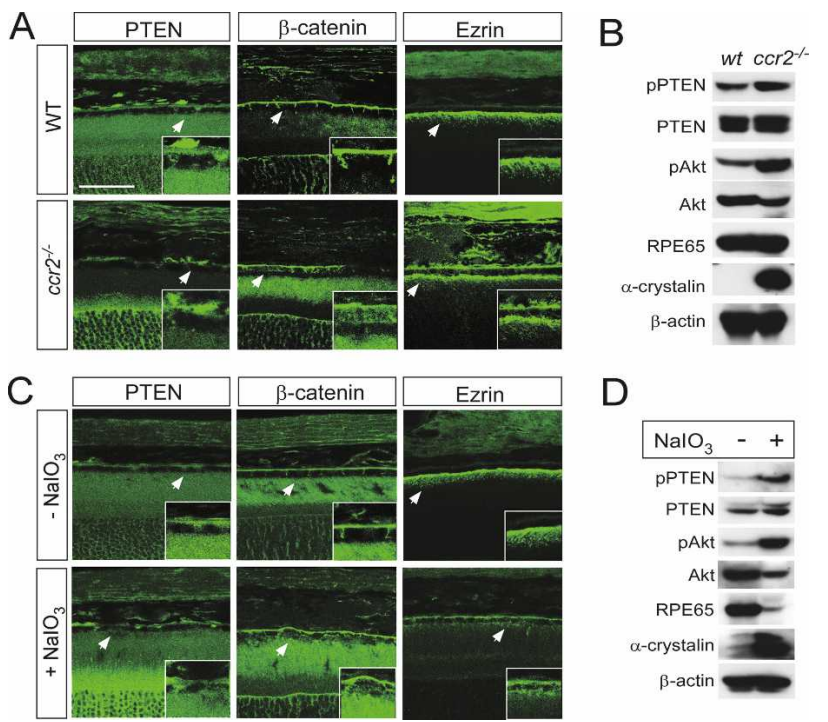

Figure 5. PTEN perturbation in RPE cells undergoing chemically and genetically induced retinal degeneration. $(A)$ Frozen sections $(10 \mu \mathrm{m})$ of 11 -mo-old wild-type or $\mathrm{ccr}^{-/-}$mouse eyes were stained with antibodies against PTEN, $\beta$-catenin, or Ezrin. (B) Relative proteins levels in RPE cells isolated from 11- to 12-mo-old wild-type or $\mathrm{ccr}^{-/-}$mice were accessed by Western blotting with anti-phospho-PTEN(S380/T382/T383) (pPTEN), anti-PTEN (PTEN), anti-phospho-Akt(S473) (pAkt), anti-Akt (Akt), $\alpha$-crystallin, or $\beta$-actin antibody. (C) C57/BL6 wild-type mice (3 mo old) were intravenously injected with $\mathrm{NaIO}_{3}$ (30 $\mathrm{mg} / \mathrm{kg}$ ), and the levels of pPTEN, pAkt, and $\beta$-catenin in RPE cells were monitored by immunostaining after $24 \mathrm{~h}$. (D) The levels of pPTEN, PTEN, pAkt, Akt, $\alpha$-crystallin, or $\beta$-actin in RPE cells from the $\mathrm{NaIO}_{3}$-injected mice were assessed by Western blotting. Arrowheads in $A$ and $C$ indicate the area magnified in each inset. Bar, $50 \mu \mathrm{m}$.

Ccr2-activated signaling pathways unrelated to RPE degeneration, we induced RPE degeneration through oxidative stress. The oxidative stressor sodium iodate $\left(\mathrm{NaIO}_{3}\right)$ has been used previously to induce selective degeneration of the RPE and consequent retinal degeneration (Ringvold et al. 1981; Kiuchi et al. 2002; Enzmann et al. 2006). Intravenous injection of $\mathrm{NaIO}_{3}$ into C57/BL6 mice induced disorganization of the RPE layer after $36 \mathrm{~h}$, and subsequently led to the degeneration of photoreceptors. Reduced immunostaining for PTEN and cytoplasmic release of $\beta$-catenin from junctional areas were also observed in the RPE cells of these $\mathrm{NaIO}_{3}$-injected mice, similar to that seen in PTEN-deficient or $c c r 2^{-/-}$RPE cells (Fig. 5C). These events were also accompanied by an increased phosphorylation of PTEN and Akt (Fig. 5D). These results suggest that the inactivation of PTEN and the consequent breakdown of AJs are not $c c r 2^{-/}$-specific events, but rather reflect a common mechanism for RPE degeneration following oxidative stress.

\section{PTEN-deficient RPE cells transform from epithelia to mesenchyme and form metastatic tumors}

PTEN is a well-known tumor suppressor, and we found that a substantial fraction of $\mathrm{fl} / \mathrm{fl}$; T1Cre adult mice car- ried tumors. However, none of these tumors were intraocular. Instead, they appeared primarily in lymph nodes, but also in the colon, intestine, ovary, testis, and liver (Supplemental Fig. S7A; data not shown). Tumors were detected as early as $3 \mathrm{mo}$, but most were observed in mice older than 6 mo (Supplemental Fig. S7E). The spleen, where transformed RPE cells have been shown previously to metastasize and induce splenomegaly (Penna et al. 1998; Mori et al. 2002), contained only entrapped pigmented cells without any notable difference in size from wildtype (Supplemental Fig. S7C). Lymph node tumors and pigmented spleens included cells with recombined PTEN genes between the two loxP sites (Supplemental Fig. S7F). Since these tissues were negative for Cre expression, the tumors are most likely to have originated from infiltrating cells. This suggests that mutant cells, from the RPE or other TRP1postive tissues, infiltrate into the blood or lymphatic vessels and migrate to the lymph nodes, from which they further migrate to other tissues to induce metastatic tumors.

Supporting this hypothesis, the level of genes specifically expressed in migratory mesenchymal cells was significantly increased in mutant RPE cells (Supplemental Table S1). These include muscle-specific genes, such as $\alpha$-SMA/ActA2a, myosin heavy-chain genes Myh1 and Myh4, troponin C, and tropomyosin (Thiery 2003; Lee et al. 2006). The elevated expression of these genes is complemented by the reduced expression of epithelialspecific genes, including the junctional protein genes listed above. We confirmed increased expression of $\alpha$ SMA and Myh1, and decreased expression of E-cadherin, desmoplakin, and Crumbs 3, by quantitative PCR (QPCR) and Western blotting (Fig. 6A,B).

The elevation of mesenchymal genes and the concomitant reduction of epithelial genes in PTEN-deficient RPE cells are commonly linked to an EMT, which is observed during cancer development as well as in embryonic cell migration (Thiery 2003; Lee et al. 2006). Thus, the acquisition of mesenchymal characteristics in PTEN-deficient RPE cells could be an initial event in metastatic tumor development in the mutant mice. We therefore examined the migratory ability of wild-type versus PTEN-deficient RPE cells in Matrigel invasion chambers (Fig. 6C,D). Wild-type RPE cells formed a single epithelial layer with strong cell-to-cell adhesion, and only marginally invaded the Matrigel membrane. In marked contrast, PTEN-deficient RPE cells migrated into the Matrigel after $7 \mathrm{~d}$ of culture, and then passed through it to grow on the lower chamber membrane. We observed an $\sim 30$-fold increase in RPE cell migration upon PTEN inactivation (Fig. 6C). Wild-type RPE cells contained well-maintained actin filament networks linked to intercellular adhesions (Fig. 6D), while the actin filaments of PTEN-deficient RPE cells were absent from cell-to-cell contacts. They instead formed prominent stress fibers, which are often seen in highly migratory cells in culture (Fig. 6D). Together, these data suggest that PTEN-deficient RPE cells failed to maintain intercellular adhesions, underwent an EMT, and invaded the 


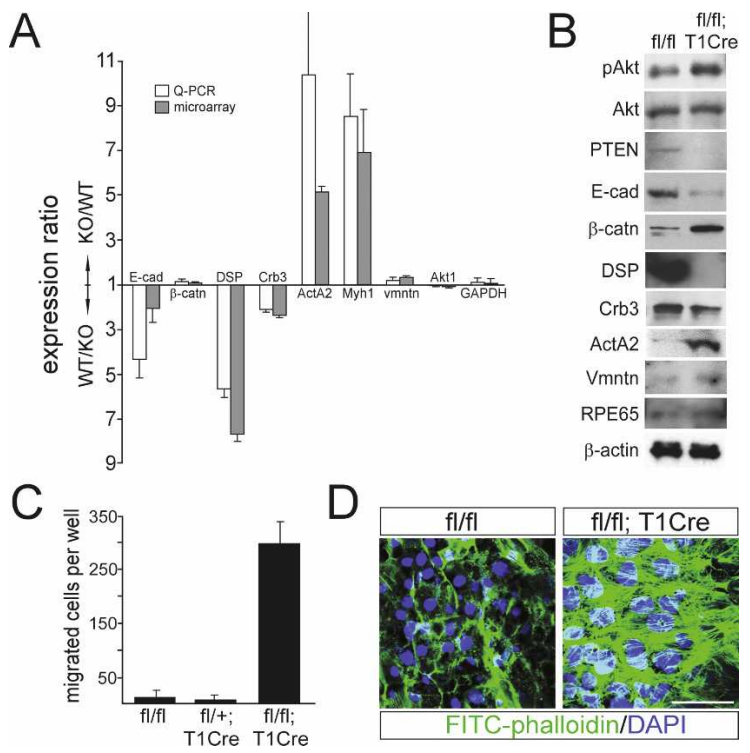

Figure 6. PTEN-deficient RPE cells lose epithelial properties and undergo an EMT. (A) Comparative analyses of gene expression patterns between wild-type (WT) and PTEN-deficient (KO) RPE cells using Q-PCR and microarrays (see Supplemental Table S1). Results are average values from triplicate (Q-PCR) or duplicate (microarray) analyses. (B) Equivalent amounts of total cell lysates from wild-type (fl/fl) or PTEN-deficient (fl/fl;T1Cre) mouse RPE cells were also analyzed by Western blotting. $(C)$ $\mathrm{RPE}$ cells isolated from $\mathrm{fl} / \mathrm{fl}, \mathrm{fl} /+$; T1Cre, or $\mathrm{fl} / \mathrm{fl}$; T1Cre mice were grown on Matrigel transwell plates for $2 \mathrm{wk}$, and the number of cells migrating into and through the Matrigel membrane were counted (see the Materials and Methods). (D) RPE cells from $\mathrm{fl} / \mathrm{fl}$ mice form an epithelial sheet on Matrigel matrix, with an intact microfilament network, as monitored by FITC-labeled phalloidin (green), at cell-to-cell adhesion sites. Stress fibers were more prominent in PTEN-deficient RPE cells isolated from $\mathrm{fl} / \mathrm{fl} ; \mathrm{T} 1 \mathrm{Cre}$ mice. Nuclei of RPE cells in 3D culture are shown by DAPI staining (blue). Bar, $50 \mu \mathrm{m}$. (E-cad) E-cadherin; $(\beta$-catn) $\beta$-catenin; (DSP) desmoplakin; (Crb3) Crumbs 3; $(\alpha-$ SMA) $\alpha$-smooth muscle actin; (vmntn) vimentin.

circulatory system to form metastatic tumors at distant sites.

To assess the potential importance of nuclear translocation of $\beta$-catenin, which was released from AJs to induce the expression of EMT-related genes (Yook et al. 2006), to these events, we crossed our RPE conditional PTEN mutants with a reporter line in which nuclear $\beta$-galactosidase (BAT-gal) expression is driven by $\beta$-catenin/T-cell factor (TCF)-responsive elements (Maretto et al. 2003). We found that the number of RPE cells containing BAT-gal was increased in $\mathrm{fl} / \mathrm{fl}$; $\mathrm{T} 1 \mathrm{Cre}$ mice relative to $\mathrm{fl} / \mathrm{fl}$ mice (Supplemental Fig. S8A). In contrast, the numbers of BAT-gal-positive cells in the ciliary body, which is enriched in Wnt signaling (Liu et al. 2006), was not significantly different (Supplemental Fig. S8B). This suggests that $\beta$-catenin/TCF-induced BAT-gal expression in PTEN-deficient RPE cells might depend not on Wnt signaling, but rather on Akt antagonism of glycogen synthase kinase $\beta$, which promotes the proteolytic degradation of cytosolic free $\beta$-catenin through phosphorylation (Cross et al. 1995; Aberle et al. 1997).

\section{Discussion}

The energy carried by light generates reactive oxidative species that can accumulate in the form of oxidized macromolecules in photoreceptors and RPE cells (Noell et al. 1966; Young and Bok 1969; Winkler et al. 1999; Wenzel et al. 2005). Genetic or age-dependent decreases in redox systems in photoreceptors or RPE cells often lead to the inefficient clearance of these agents, which promote retinal degeneration. Photoreceptors and RPE cells employ several mechanisms to protect themselves from oxidative byproducts. Photoreceptor-intrinsic survival programs, for example, protect photoreceptors from lightactivated cell death (Doonan and Cotter 2004). In addition, photoreceptors transfer toxic metabolites to RPE cells, which are responsible for their elimination through metabolic conversion or delivery to the blood. RPE cells are also involved in the phagocytic elimination of dead or damaged photoreceptors (Young and Bok 1969; Edwards and Szamier 1977; Bok 1993). However, less is known about protective programs that are intrinsic to RPE cells, despite the fact that defects in these cells are major causes of retinal degenerative diseases such as AMD (Hamdi and Kenney 2003; Zarbin 2004; Sparrow and Boulton 2005). Our data now demonstrate that loss of PTEN activity in RPE cells, either by cell type-specific gene deletion or through functional inactivation brought on by oxidative stress, results in retinal degeneration that is initiated by a loss of structural integrity of PTENdependent intercellular adhesions.

The observation that PTEN is inactivated by $\mathrm{NaIO}_{3}$ links the pathology of retinal degenerative diseases to the cellular events, which we observed in PTEN-deficient RPE cells. Retinal degeneration in $\mathrm{fl} / \mathrm{fl}$; T1Cre mice shares many anatomical and physiological features with AMD, which is induced by the cumulative stress generated by oxidative metabolites (Zarbin 2004; Decanini et al. 2007). A gradual loss of RPE cells and a subsequent degeneration of photoreceptors, for example, are observed in both instances (Fig. 2; Supplemental Figs. S1, $\mathrm{S} 2$ ), as is macrophage infiltration into the retina, disruption of BRB structures, gliosis, and neovascularization (Supplemental Fig. S3; data not shown). This is also the case for regression of inter-RPE junctional structures (Figs. 3, 5; Supplemental Fig. S4). Finally, PTEN is inactivated and lost from junctional areas in AMD model $c_{c r 2^{-/}}$RPE cells, mimicking that seen in PTEN-deficient RPE cells (Fig. 5A). These multiple concordances suggest that depletion of PTEN function in RPE cells, either by somatic mutation or oxidative stress, can lead to AMD.

The molecular mechanisms that result in PTEN depletion and/or inactivation by $\mathrm{NaIO}_{3}$ and other AMD-triggering signals (such as cigarette smoking) remain to be elucidated. A recent report suggests a potential link between PI3K activation and AMD (Barbieri and Weksler 2007), in that extracts of tobacco smoke were found to 
activate Akt and disrupt intercellular junctional structures in endothelium, as we observe in PTEN-deficient and $\mathrm{NaIO}_{3}$-damaged $\mathrm{RPE}$ cells (Figs. 3, 5B; Supplemental Fig. S4). Together, these results suggest that oxidative stressors might activate PI3K-Akt signaling pathways in RPE cells to induce AMD pathology.

The phosphorylation of PTEN at S380/T382/T383 not only decreases its enzymatic activity, but also interferes with its association with PDZ domain-containing proteins (Adey et al. 2000; Vazquez et al. 2000). Consistent with this, we find that the concentration of PTEN at junctional areas is lost in $\mathrm{ccr}^{-/-}$and $\mathrm{NaIO}_{3}$-treated RPE cells, even though the overall level of PTEN is not different from wild type (Fig. 5). Phosphorylation at these residues has been suggested to change the conformation of PTEN, burying the phosphatase active site and PDZbinding domain inside a folded protein (Vazquez et al. 2001; Das et al. 2003). This would prevent the phosphorylated PTEN in $\mathrm{ccr}^{-/-}$and $\mathrm{NaIO}_{3}$-treated RPE cells from participating in junctional events in a manner similar to that seen for PTEN that lacks a PDZ-binding domain entirely (Fig. 4). A recent report demonstrates the importance of the C-terminal PDZ-binding domain for the maintenance of epithelial features in chick primitive streak cells (Leslie et al. 2007). These findings, in concert with our observations, emphasize the critical role that PTEN plays in the organization of epithelial junctional structures.

PTEN is also thought to regulate junctional structures by dephosphorylating junctional proteins and by generating PIP2 from PIP3 (Tamura et al. 1998; Kotelevets et al. 2001, 2005). Our demonstration that junctional $\beta$ catenin is recovered by reintroduction of PTEN(G129E), a mutant that possesses protein phosphatase activity, strongly suggests that this activity plays a important role in the maintenance of intercellular junctional structures at least in part (Fig. 4). Leslie et al. (2007) similarly have found that the protein phosphatase activity of PTEN is necessary for the suppression of EMT, while its lipid phosphatase activity is dispensable.

Little is known about the PTEN substrates that mediate epithelial cell junctional integrity (Salmena et al. 2008). We found that tyrosine phosphorylation of $\beta$-catenin, which is a recognized PTEN substrate (Vogelmann et al. 2005), was increased in PTEN-deficient RPE cells (Supplemental Fig. S9A). Hyperphosphorylation of $\beta$-catenin on tyrosine residues decreases its binding affinity for E-cadherin, and releases it into cytoplasm (Lilien and Balsamo 2005; Vogelmann et al. 2005); and the binding of the E-cadherin cytoplasmic domain to $\beta$ catenin was reduced in PTEN-deficient RPE cells compared with wild-type RPE (Supplemental Fig. S9B). These results suggest that PTEN complexes with AJ components via its PDZ-binding domain, and dephosphorylates junctional proteins, including $\beta$-catenin, thereby promoting their stable association with E-cadherin. At the same time, PTEN also converts PIP3, which is usually higher at cell-to-cell contact regions in epithelial cells (Kotelevets et al. 2005; Martin-Belmonte et al. 2007), to PIP2, which inhibits downstream events that are normally activated by PIP3.
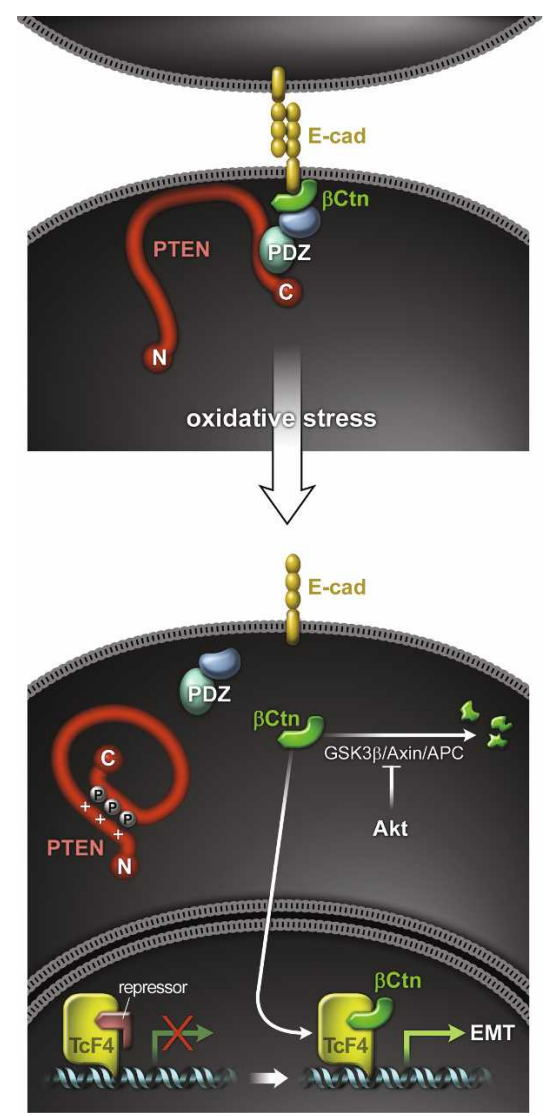

Figure 7. Schematic diagram of pathological signaling pathways in PTEN-inactivated RPE cells. (Top) PTEN normally functions as a component of AJs in healthy RPE cells, through its interaction with junctional PDZ proteins. This requires the C-terminal PDZ-binding domain of PTEN. (Bottom) PTEN is lost from junctional structures by phosphorylational inactivation upon oxidative stress or somatic mutation. $\beta$-Catenin is then released from dissociated junctional complexes, and enters the nucleus. RPE cells are thereby transformed into highly migratory mesenchymal cells, through $\beta$-catenin/TCF induction of new mesenchymal genes.

As summarized in Figure 7, our results indicate that PTEN is located at a pivotal node in the RPE cell signaling pathways that regulate junctional integrity. Oxidative stressors, which accumulate during phototransduction, activate signaling pathways that induce the inactivation of PTEN by phosphorylation. A reduction in PTEN activity results in a shift in signaling, from the maintenance to the disruption of intercellular junctional structures. At the same time, the same oxidative stressors trigger the RPE degeneration that underlies many retinal degenerative diseases.

\section{Materials and methods}

Mouse lines

PTEN $^{\text {flox }}$ mice (Suzuki et al. 2001) were bred with TRP1-Cre mice (Mori et al. 2002) to generate PTEN ${ }^{\text {flox/flox }}$;TRP1-Cre (fl/ $\mathrm{fl}$ T1Cre) mice. $\mathrm{Ccr2} 2^{-/-}$and $\mathrm{Ccl} 2^{-/-}$mice were purchased from The Jackson Laboratories. 


\section{DNA constructs}

cDNA clones of PTEN(399X) and PTEN(M-CBR3) were obtained by generous gifts from Dr. Nick Leslie (University of Dundee), and were subcloned into the EcoRI/SalI site of the pBabe-Puro retroviral vector for the generation of retroviruses expressing deletion mutant PTEN genes. pBabe-Puro constructs expressing PTEN, PTEN(G129R), or PTEN(G129E) were obtained from Dr. Frank Furnari (Ludwig Institute for Cancer Research, University of California at San Diego).

\section{RPE isolation, primary cell culture, and Matrigel invasion assays}

Primary mouse RPE cells were isolated from p21 wild-type or PTEN $^{\mathrm{fl} / \mathrm{fl}}$;TRP1-Cre mice as described (Bonilha et al. 1999; Prasad et al. 2006). In brief, enucleated eyes were treated with hyaluronidase $(200 \mathrm{U} / \mathrm{mL})$ for $30 \mathrm{~min}$ before treatment with tryp$\sin (2 \mathrm{mg} / \mathrm{mL})$ for $30 \mathrm{~min}$. Cells were dissociated with $0.25 \%$ trypsin-EDTA for $5 \mathrm{~min}$, and pigmented RPE cells were counted with a hemocytometer. Isolated RPE cells $\left(\sim 10^{3}\right)$ then plated on 10-mm Matrigel-coated transwell plates (BD) in Dulbecco's modified eagles media (DMEM; Invitrogen) supplemented with $10 \%$ fetal bovine serum (FBS; Hyclone), 1\% penicillin/streptomycin (Invitrogen). After reaching confluence, cells were infected with retroviruses or treated with chemical reagents. For invasion analyses, RPE cells grown on Matrigel transwells were scraped away with a cotton bar, and the Matrigel membranes were fixed in $4 \%$ paraformaldehyde/PBS (PFA/PBS) followed by staining with DAPI to monitor cells that had invaded the filters. The numbers of cells inside or on the opposite side of the membranes were added to the numbers of cells located at the well bottom to yield total invasive cells.

\section{Retrovirus preparation and infection}

Phoenix cells, which were maintained in DMEM with $10 \%$ FBS, were transfected with pBabe-Puro-PTEN DNA constructs to produce retroviruses expressing wild-type or mutant versions of PTEN. Forty-eight hours after transfection, culture medium was collected and filtered through a $0.45-\mu \mathrm{m}$ filter (Millipore) followed by mixing with $10 \mu \mathrm{g} / \mathrm{mL}$ polybrene (Specialty Media) prior to application to primary cultured RPE cells. Medium containing viruses was removed after $12 \mathrm{~h}$, and then changed to fresh DMEM with $10 \%$ FBS prior to incubation for a further $24 \mathrm{~h}$.

\section{Antibodies and immunohistochemistry}

For immunohistochemistry of frozen sections, mice were anesthetized with tribromoethanol (1 mg/ $\mathrm{kg}$; Aldrich) and perfused with $4 \%$ PFA/PBS. Isolated eyes were further fixed with $4 \%$ PFA/PBS for $1 \mathrm{~h}$ prior to incubation in $20 \%$ sucrose/PBS for 16 $\mathrm{h}$ followed by freezing in OCT cryopreservation medium. Frozen sections of OCT-embedded eyes were incubated in blocking solution-10\% normal donkey serum or $10 \%$ normal goat serum in PBS with $0.1 \%$ Triton X-100-for $1 \mathrm{~h}$ prior to incubation with primary antibodies at $4^{\circ} \mathrm{C}$ for $16 \mathrm{~h}$ The primary antibodies used in this study are listed in Supplemental Table S2. Fluorescent images were obtained with a confocal microscope (LSM510; Zeiss) after staining with Alexa488 (Molecular Probes) or Cy3-conjugated (Jackson Laboratory) anti-mouse or anti-rabbit antibodies for $1 \mathrm{~h}$.

Immunotaining of primary cultured RPE cells grown on Matrigel transwell plates was conducted as described (Bonilha et al. 1999). Briefly, confluent RPE cells on Matrigel were fixed with
4\% paraformaldehyde (PFA) in PBS with $\mathrm{Ca}^{2+} / \mathrm{Mg}^{2+}$ (PBS-CM) for $10 \mathrm{~min}$, and treated with 4\% PFA in PBS-CM for $10 \mathrm{~min}$, and $4 \%$ PFA in PBS-CM and $1 \%$ Triton X-100 for 15 min. Cells were stained with appropriate antibodies.

\section{$\mathrm{NaIO}_{3}$ injection and RPE lysate preparation}

C57/BL6 mice (2 to 3 mo) were injected with $\mathrm{NaIO}_{3}$ solution (30 $\mathrm{mg} / \mathrm{kg}$ in PBS) into tail veins as described previously (Kiuchi et al. 2002; Enzmann et al. 2006). Eyes were enucleated and the retina carefully pushed out before treating with dispase (100 $\mathrm{U} / \mathrm{mL}$ ) to isolate RPE cells. RPE cells were then lysed in a solution containing $100 \mathrm{mM}$ Tris ( $\mathrm{pH} 7.5), 150 \mathrm{mM} \mathrm{NaCl}, 1 \%$ Triton X-100, $0.1 \%$ SDS, and protease inhibitor cocktails (Roche). Supernatants were obtained by centrifugation at $15,000 \mathrm{~g}$ for $10 \mathrm{~min}$, and were subjected to SDS-PAGE followed by Western blotting with appropriate antibodies.

\section{Acknowledgments}

We thank Dr. Pierre Chambon for the generous gift of TRP1-Cre mice, Dr. Stefano Piccolo for BAT-gal mice, Dr. Nick Leslie for human PTEN and its mutant clones, Dr. Frank Furnari for pBabe-Puro-PTEN and mutant constructs, Dr. Masatoshi Takeichi for GST-E-cadherin, Dr. Benjamin Margolis for Crb3 antibody, and Joe Hash and Namsuk Kim for outstanding technical support. This work was supported by the Research Program for New Drug Target Discovery (M10748000222-08N4800-22210; J.W.K.) and Stem Cell Research (M10641000055-07N410005510; J.W.K.), grants from the Korean Ministry of Science and Technology (CDA0004/2007-C; J.W.K), an HFSP Career Development Award (J.W.K.), and the NIH (G.L.).

\section{References}

Aberle, H., Bauer, A., Stappert, J., Kispert, A., and Kemler, R. 1997. $\beta$-Catenin is a target for the ubiquitin-proteasome pathway. EMBO J. 16: 3797-3804.

Adey, N.B., Huang, L., Ormonde, P.A., Baumgard, M.L., Pero, R., Byreddy, D.V., Tavtigian, S.V., and Bartel, P.L. 2000. Threonine phosphorylation of the MMAC1/PTEN PDZ binding domain both inhibits and stimulates PDZ binding. Cancer Res. 60: 35-37.

Adler, R., Curcio, C., Hicks, D., Price, D., and Wong, F. 1999. Cell death in age-related macular degeneration. Mol. Vis. 5: 31.

Ambati, J., Anand, A., Fernandez, S., Sakurai, E., Lynn, B.C., Kuziel, W.A., Rollins, B.J., and Ambati, B.K. 2003. An animal model of age-related macular degeneration in senescent Ccl2- or Ccr-2-deficient mice. Nat. Med. 9: 1390-1397.

Bailey, T.A., Kanuga, N., Romero, I.A., Greenwood, J., Luthert, P.J., and Cheetham, M.E. 2004. Oxidative stress affects the junctional integrity of retinal pigment epithelial cells. Invest. Ophthalmol. Vis. Sci. 45: 675-684.

Barbieri, S.S. and Weksler, B.B. 2007. Tobacco smoke cooperates with interleukin-1 $\beta$ to alter $\beta$-catenin trafficking in vascular endothelium resulting in increased permeability and induction of cyclooxygenase-2 expression in vitro and in vivo. FASEB J. 8: 1831-1843.

Barbieri, S.S., Ruggiero, L., Tremoli, E., and Weksler, B.B. 2008. Suppressing PTEN activity by tobacco smoke plus interleukin-1 $\beta$ modulates dissociation of VE-cadherin/ $\beta$-catenin complexes in endothelium. Arterioscler. Thromb. Vasc. Biol. 28: 732-738.

Barker, N. and Clevers, H. 2000. Catenins, Wnt signaling and 
cancer. Bioessays 22: 961-965.

Beatty, S., Koh, H., Phil, M., Henson, D., and Boulton, M. 2000. The role of oxidative stress in the pathogenesis of age-related macular degeneration. Surv. Ophthalmol. 45: 115-134.

Bok, D. 1993. The retinal pigment epithelium: A versatile partner in vision. J. Cell Sci. Suppl. 17: 189-195.

Bonilha, V.L., Finnemann, S.C., and Rodriguez-Boulan, E. 1999. Ezrin promotes morphogenesis of apical microvilli and basal infoldings in retinal pigment epithelium. J. Cell Biol. 147: $1533-1548$

Bringmann, A. and Reichenbach, A. 2001. Role of Muller cells in retinal degenerations. Front. Biosci. 6: E72-E92.

Cai, J., Nelson, K.C., Wu, M., Sternberg Jr., P., and Jones, D.P. 2000. Oxidative damage and protection of the RPE. Prog Retin. Eye Res. 19: 205-221.

Cantley, L.C. 2002. The phosphoinositide 3-kinase pathway. Science 296: 1655-1657.

Cross, D.A., Alessi, D.R., Cohen, P., Andjelkovich, M., and Hemmings, B.A. 1995. Inhibition of glycogen synthase kinase- 3 by insulin mediated by protein kinase B. Nature 378 : 785-789.

Das, S., Dixon, J.E., and Cho, W. 2003. Membrane-binding and activation mechanism of PTEN. Proc. Natl. Acad. Sci. 100: 7491-7496.

Decanini, A., Nordgaard, C.L., Feng, X., Ferrington, D.A., and Olsen, T.W. 2007. Changes in select redox proteins of the retinal pigment epithelium in age-related macular degeneration. Am. J. Ophthalmol. 143: 607-615.

Defoe, D.M. and Grindstaff, R.D. 2004. Epidermal growth factor stimulation of RPE cell survival: Contribution of phosphatidylinositol 3-kinase and mitogen-activated protein kinase pathways. Exp. Eye Res. 79: 51-59.

Doonan, F. and Cotter, T.G. 2004. Apoptosis: A potential therapeutic target for retinal degenerations. Curr. Neurovasc. Res. 1: 41-53.

Edwards, R.B. and Szamier, R.B. 1977. Defective phagocytosis of isolated rod outer segments by RCS rat retinal pigment epithelium in culture. Science 197: 1001-1003.

Enzmann, V., Row, B.W., Yamauchi, Y., Kheirandish, L., Gozal, D., Kaplan, H.J., and McCall, M.A. 2006. Behavioral and anatomical abnormalities in a sodium iodate-induced model of retinal pigment epithelium degeneration. Exp. Eye Res. 82: 441-448.

Furnari, F.B., Lin, H., Huang, H.S., and Cavenee, W.K. 1997. Growth suppression of glioma cells by PTEN requires a functional phosphatase catalytic domain. Proc. Natl. Acad. Sci. 94: $12479-12484$

Georgescu, M.M., Kirsch, K.H., Akagi, T., Shishido, T., and Hanafusa, H. 1999. The tumor-suppressor activity of PTEN is regulated by its carboxyl-terminal region. Proc. Natl. Acad. Sci. 96: 10182-10187.

Georgescu, M.M., Kirsch, K.H., Kaloudis, P., Yang, H., Pavletich, N.P., and Hanafusa, H. 2000. Stabilization and productive positioning roles of the C2 domain of PTEN tumor suppressor. Cancer Res. 60: 7033-7038.

Grierson, I., Hiscott, P., Hogg, P., Robey, H., Mazure, A., and Larkin, G. 1994. Development, repair and regeneration of the retinal pigment epithelium. Eye 8: 255-262.

Hamdi, H.K. and Kenney, C. 2003. Age-related macular degeneration: A new viewpoint. Front. Biosci. 8: 305-314.

Horwitz, J. 2000. The function of $\alpha$-crystallin in vision. Semin. Cell Dev. Biol. 11: 53-60.

Jamora, C. and Fuchs, E. 2002. Intercellular adhesion, signalling and the cytoskeleton. Nat. Cell Biol. 4: 101-108.

Jin, M., Barron, E., He, S., Ryan, S.J., and Hinton, D.R. 2002. Regulation of RPE intercellular junction integrity and func- tion by hepatocyte growth factor. Invest. Ophthalmol. Vis Sci. 43: 2782-2790.

Kiuchi, K., Yoshizawa, K., Shikata, N., Moriguchi, K., and Tsubura, A. 2002. Morphologic characteristics of retinal degeneration induced by sodium iodate in mice. Curr. Eye Res. 25: $373-379$

Kotelevets, L., van Hengel, J., Bruyneel, E., Mareel, M., van Roy, F., and Chastre, E. 2001. The lipid phosphatase activity of PTEN is critical for stabilizing intercellular junctions and reverting invasiveness. J. Cell Biol. 155: 1129-1135.

Kotelevets, L., van Hengel, J., Bruyneel, E., Mareel, M., van Roy, F., and Chastre, E. 2005. Implication of the MAGI-1b/PTEN signalosome in stabilization of adherens junctions and suppression of invasiveness. FASEB J. 19: 115-117.

Lee, J.O., Yang, H., Georgescu, M.M., Di Cristofano, A., Maehama, T., Shi, Y., Dixon, J.E., Pandolfi, P., and Pavletich, N.P. 1999. Crystal structure of the PTEN tumor suppressor: Implications for its phosphoinositide phosphatase activity and membrane association. Cell 99: 323-334.

Lee, S.R., Yang, K.S., Kwon, J., Lee, C., Jeong, W., and Rhee, S.G. 2002. Reversible inactivation of the tumor suppressor PTEN by $\mathrm{H}_{2} \mathrm{O}_{2}$. J. Biol. Chem. 277: 20336-20342.

Lee, J.M., Dedhar, S., Kalluri, R., and Thompson, E.W. 2006. The epithelia-mesenchymal transition: New insights in signaling, development, and disease. J. Cell Biol. 172: 973-981.

Leslie, N.R., Gray, A., Pass, I., Orchiston, E.A., and Downes, C.P. 2000. Analysis of the cellular functions of PTEN using catalytic domain and C-terminal mutations: Differential effects of C-terminal deletion on signalling pathways downstream of phosphoinositide 3-kinase. Biochem. I. 346: 827833.

Leslie, N.R., Bennett, D., Lindsay, Y.E., Stewart, H., Gray, A., and Downes, C.P. 2003. Redox regulation of PI 3-kinase signalling via inactivation of PTEN. EMBO J. 22: 5501-5510.

Leslie, N.R., Yang, X., Downes, C.P., and Weijer, C.J. 2007. PtdIns $(3,4,5) \mathrm{P}(3)$-dependent and -independent roles for PTEN in the control of cell migration. Curr. Biol. 17: 115-125.

Li, J., Yen, C., Liaw, D., Podsypanina, K., Bose, S., Wang, S.I., Puc, J., Miliaresis, C., Rodgers, L., McCombie, R., et al. 1997. PTEN, a putative protein tyrosine phosphatase gene mutated in human brain, breast, and prostate cancer. Science 275: 1943-1947.

Lilien, J. and Balsamo, J. 2005. The regulation of cadherin-mediated adhesion by tyrosine phosphorylation/dephosphorylation of $\beta$-catenin. Curr. Opin. Cell Biol. 17: 459-465.

Liu, H., Thurig, S., Mohamed, O., Dufort, D., and Wallace, V.A. 2006. Mapping canonical Wnt signaling in the developing and adult retina. Invest. Ophthalmol. Vis. Sci. 47: 50885097.

Livesey, F.J. and Cepko, C.L. 2001. Vertebrate neural cell-fate determination: Lessons from the retina. Nat. Rev. Neurosci. 2: 109-118.

Maehama, T. and Dixon, J.E. 1998. The tumor suppressor, PTEN/MMAC1, dephosphorylates the lipid second messenger, phosphatidylinositol 3,4,5-trisphosphate. J. Biol. Chem. 273: $13375-13378$.

Malorny, U., Michels, E., and Sorg, C. 1986. A monoclonal antibody against an antigen present on mouse macrophages and absent from monocytes. Cell Tissue Res. 243: 421-428.

Maretto, S., Cordenonsi, M., Dupont, S., Braghetta, P., Broccoli, V., Hassan, A.B., Volpin, D., Bressan, G.M., and Piccolo, S. 2003. Mapping Wnt $/ \beta$-catenin signaling during mouse development and in colorectal tumors. Proc. Natl. Acad. Sci. 100: 3299-3304.

Marmorstein, A.D., Finnemann, S.C., Bonilha, V.L., and Rodriguez-Boulan, E. 1998. Morphogenesis of the retinal pig- 
ment epithelium: Toward understanding retinal degenerative diseases. Ann. N. Y. Acad. Sci. 857: 1-12.

Martin-Belmonte, F., Gassama, A., Datta, A., Yu, W., Rescher, U., Gerke, V., and Mostov, K. 2007. PTEN-mediated apical segregation of phosphoinositides controls epithelial morphogenesis through Cdc42. Cell 128: 383-397.

Mori, M., Metzger, D., Garnier, J.M., Chambon, P., and Mark, M. 2002. Site-specific somatic mutagenesis in the retinal pigment epithelium. Invest. Ophthalmol. Vis. Sci. 43: 13841388.

Morrow, E.M., Furukawa, T., and Cepko, C.L. 1998. Vertebrate photoreceptor cell development and disease. Trends Cell Biol. 8: 353-358. 7

Myers, M.P., Stolarov, J.P., Eng, C., Li, J., Wang, S.I., Wigler, M.H., Parsons, R., and Tonks, N.K. 1997. P-TEN, the tumor suppressor from human chromosome 10q23, is a dual-specificity phosphatase. Proc. Natl. Acad. Sci. 94: 9052-9057.

Myers, M.P., Pass, I., Batty, I.H., Van der Kaay, J., Stolarov, J.P., Hemmings, B.A., Wigler, M.H., Downes, C.P., and Tonks, N.K. 1998. The lipid phosphatase activity of PTEN is critical for its tumor supressor function. Proc. Nat1. Acad. Sci. 95: 13513-13518.

Noell, W.K., Walker, V.S., Kang, B.S., and Berman, S. 1966. Retinal damage by light in rats. Invest. Ophthalmol. 5: 450-473.

Penna, D., Schmidt, A., and Beermann, F. 1998. Tumors of the retinal pigment epithelium metastasize to inguinal lymph nodes and spleen in tyrosinase-related protein 1/SV40 T antigen transgenic mice. Oncogene 17: 2601-2607.

Perez-Moreno, M., Jamora, C., and Fuchs, E. 2003. Sticky business: Orchestrating cellular signals at adherens junctions. Cell 112: 535-548.

Pinal, N., Goberdhan, D.C., Collinson, L., Fujita, Y., Cox, I.M., Wilson, C., and Pichaud, F. 2006. Regulated and polarized PtdIns(3,4,5)P3 accumulation is essential for apical membrane morphogenesis in photoreceptor epithelial cells. Curr. Biol. 16: 140-149.

Prasad, D., Rothlin, C.V., Burrola, P., Burstyn-Cohen, T., Lu, Q., Garcia de Frutos, P., and Lemke, G. 2006. TAM receptor function in the retinal pigment epithelium. Mol. Cell. Neurosci. 33: 96-108.

Ringvold, A., Olsen, E.G., and Flage, T. 1981. Transient breakdown of the retinal pigment epithelium diffusion barrier after sodium iodate: A fluorescein angiographic and morphological study in the rabbit. Exp. Eye Res. 33: 361-369.

Rizzolo, L.J. 1997. Polarity and the development of the outer blood-retinal barrier. Histol. Histopathol. 12: 1057-1067.

Salmena, L., Carracedo, A., and Pandolfi, P.P. 2008. Tenets of PTEN tumor suppression. Cell 133: 403-414.

Schraermeyer, U. and Heimann, K. 1999. Current understanding on the role of retinal pigment epithelium and its pigmentation. Pigment Cell Res. 12: 219-236.

Sparrow, J.R. and Boulton, M. 2005. RPE lipofuscin and its role in retinal pathobiology. Exp. Eye Res. 80: 595-606.

Steck, P.A., Pershouse, M.A., Jasser, S.A., Yung, W.K., Lin, H., Ligon, A.H., Langford, L.A., Baumgard, M.L., Hattier, T., Davis, T., et al. 1997. Identification of a candidate tumour suppressor gene, MMACl, at chromosome 10q23.3 that is mutated in multiple advanced cancers. Nat. Genet. 15: 356-362.

Suzuki, A., Yamaguchi, M.T., Ohteki, T., Sasaki, T., Kaisho, T., Kimura, Y., Yoshida, R., Wakeham, A., Higuchi, T., Fukumoto, M., et al. 2001. T cell-specific loss of Pten leads to defects in central and peripheral tolerance. Immunity 14: 523-534.

Tamura, M., Gu, J., Matsumoto, K., Aota, S., Parsons, R., and Yamada, K.M. 1998. Inhibition of cell migration, spreading, and focal adhesions by tumor suppressor PTEN. Science 280:
$1614-1617$.

Thiery, J.P. 2003. Epithelial-mesenchymal transitions in development and pathologies. Curr. Opin. Cell Biol. 15: 740-746.

Tolkacheva, T., Boddapati, M., Sanfiz, A., Tsuchida, K., Kimmelman, A.C., and Chan, A.M. 2001. Regulation of PTEN binding to MAGI-2 by two putative phosphorylation sites at threonine 382 and 383. Cancer Res. 61: 4985-4989.

Vasioukhin, V., Bauer, C., Yin, M., and Fuchs, E. 2000. Directed actin polymerization is the driving force for epithelial cellcell adhesion. Cell 100: 209-219.

Vazquez, F., Ramaswamy, S., Nakamura, N., and Sellers, W.R. 2000. Phosphorylation of the PTEN tail regulates protein stability and function. Mol. Cell. Biol. 20: 5010-5018.

Vazquez, F., Grossman, S.R., Takahashi, Y., Rokas, M.V., Nakamura, N., and Sellers, W.R. 2001. Phosphorylation of the PTEN tail acts as an inhibitory switch by preventing its recruitment into a protein complex. J. Biol. Chem. 276: 48627-48630.

Vogelmann, R., Nguyen-Tat, M.D., Giehl, K., Adler, G., Wedlich, D., and Menke, A. 2005. TGFß-induced downregulation of E-cadherin-based cell-cell adhesion depends on PI3kinase and PTEN. J. Cell Sci. 118: 4901-4912.

Wang, K. and Spector, A. 2000. $\alpha$-Crystallin prevents irreversible protein denaturation and acts cooperatively with other heat-shock proteins to renature the stabilized partially denatured protein in an ATP-dependent manner. Eur. I. Biochem. 267: 4705-4712.

Wenzel, A., Grimm, C., Samardzija, M., and Reme, C.E. 2005. Molecular mechanisms of light-induced photoreceptor apoptosis and neuroprotection for retinal degeneration. Prog. Retin. Eye Res. 24: 275-306.

Winkler, B.S., Boulton, M.E., Gottsch, J.D., and Sternberg, P. 1999. Oxidative damage and age-related macular degeneration. Mol. Vis. 5: 32.

Yang, P., Peairs, J.J., Tano, R., and Jaffe, G.J. 2006. Oxidantmediated Akt activation in human RPE cells. Invest. Ophthalmol. Vis. Sci. 47: 4598-4606.

Yook, J.I., Li, X.Y., Ota, I., Hu, C., Kim, H.S., Kim, N.H., Cha, S.Y., Ryu, J.K., Choi, Y.J., Kim, J., et al. 2006. A Wnt-Axin2GSK3 $\beta$ cascade regulates Snaill activity in breast cancer cells. Nat. Cell Biol. 8: 1398-1406.

Young, R.W. and Bok, D. 1969. Participation of the retinal pigment epithelium in the rod outer segment renewal process. J. Cell Biol. 42: 392-403.

Zarbin, M.A. 1998. Age-related macular degeneration: Review of pathogenesis. Eur. J. Ophthalmol. 8: 199-206.

Zarbin, M.A. 2004. Current concepts in the pathogenesis of agerelated macular degeneration. Arch. Ophthalmol. 122: 598614. 


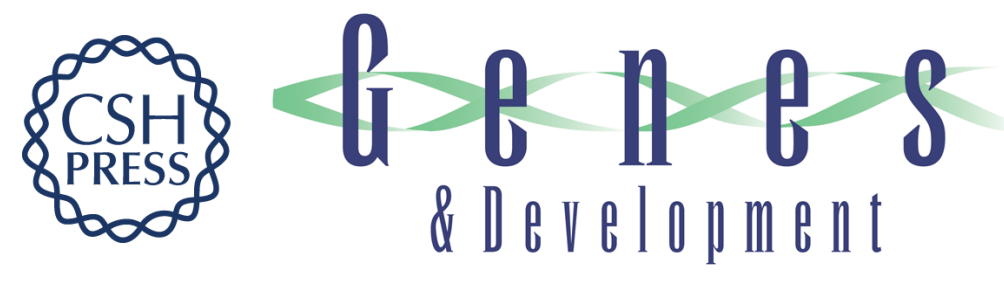

\section{Retinal degeneration triggered by inactivation of PTEN in the retinal pigment epithelium}

Jin Woo Kim, Kyung Hwa Kang, Patrick Burrola, et al.

Genes Dev. 2008, 22: originally published online November 7, 2008

Access the most recent version at doi:10.1101/gad.1700108

\section{Supplemental http://genesdev.cshlp.org/content/suppl/2008/11/05/gad.1700108.DC1 Material}

References This article cites 78 articles, 32 of which can be accessed free at: http://genesdev.cshlp.org/content/22/22/3147.full.html\#ref-list-1

\section{License}

Email Alerting

Receive free email alerts when new articles cite this article - sign up in the box at the top Service 